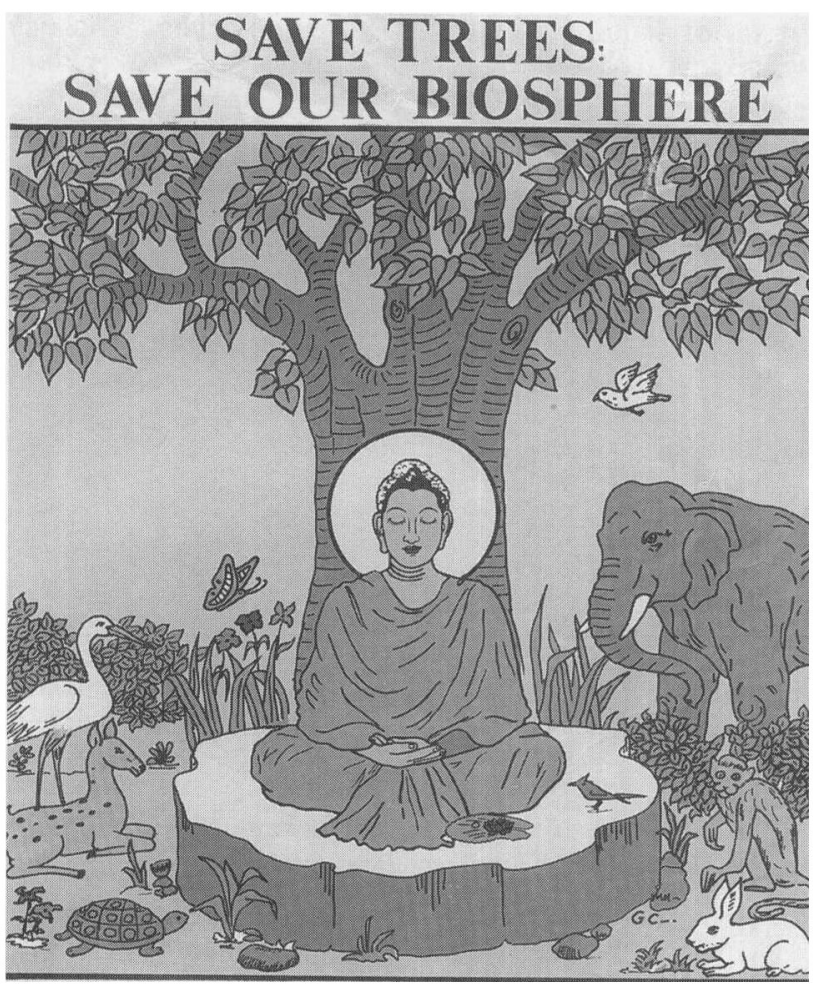

INTERNATIONAL SOCIETY OF NATURALISTS

FIG. 4. Save Trees: Save Our Biosphere Poster on 'Buddhist Perception of Nature'.

due realization that, whereas the trees and wildlife can live without Man, he cannot well continue without them!

We plead for understanding support for our modest attempts, from interested NGOs and individuals throughout the world, to activate and advance this Movement to Save Our Biosphere. We appeal to all who are convinced of such needs, to celebrate 'Every Day (as) A Biosphere Day' in their day-to-day lives - to pave the way for an equitably sustainable future for Mankind and Nature. People everywhere should realize that their civilization is really an integral part of Nature. Human survival is de- pendent upon the well-being of The Biosphere and our prudent use of the living resources of the Earth. If only Mankind would realize these fundamental truths and act rationally, 'sustainable development' should follow.

\section{REFERENCES}

Gaekwad, Fatehsinghrao P. \& Oza, G.M. (1981). Save Our Biosphere. Environmental Conservation, 8(2), pp. 117-8, fig.

OZA, G.M. (1982). Save trees, save our Biosphere! Environmental Conservation, 9(3), pp. 255-6, 1 fig.

OzA, G.M. (1986). 'Save Our Biosphere' campaign for wildlife conservation. Environmental Conservation, 13(1), pp. 75-6. 3 figs.

OZA, G.M. (1989). INSONA changes thrust and name to International Society of Naturalists. Environmental Conservation, 16(3), pp. 271-2.

OzA, G.M. (1990). Conservation activities initiated by the International Society of Naturalists (INSONA). Environmental Conservation, 17(1), pp. 81-2, 2 figs.

OzA, G.M. (1991). Editorial - Every Day A Biosphere Day. Environmental Awareness, 14(3), pp. 8I-2, fig.

Oza, Premlata \& Oza, Gunavant M. (1993). International Conference on Environmental Education in the Commonwealth, held at the University of Bradford, Bradford, England, UK, during 18-23 July 1993. Environmental Conservation, 20(4), pp. 371-2.

POLUNIN, NiCHOLAS (1991). Declaration of Biosphere Day. Environmental Conservation, 18(2), p. 118.

Polunin, Nicholas (1992). Biosphere Day and its needed Fund and Prizes. Environmental Conservation, 19(3), p. 193.

Polunin, Nicholas (1993). Introducing Biosphere Clubs. Environmental Conservation, $\mathbf{2 0}(1)$, p. 3.

Polunin, Nicholas (1994). Biosphere Day, Prizes, and Clubs. Environmental Conservation, 21(2), p. 97

PRemlata Oza,

Joint Secretary of INSONA \& Managing

Editor of Environmental Awareness;

Trustee of the Foundation for

Environmental Awareness,

$\&$

Gunavant M. Oza, President

The Foundation for Environmental Awareness; General Secretary of INSONA and

Founding Editor of Environmental Awareness Oza Building

Salatwada

Baroda 390001

India.

\title{
Optimum Human Population About One-third of Present Number
}

$\mathrm{U}$ Jntil Cultures change radically, the optimum number of people to exist on the planet at any one time lies in the vicinity of 1.5 to 2 [thousand million] people', three California ecologists estimated in an article published recently in the journal Population and Environment.

Gretchen C. Daily, of the Energy and Resources Group at the University of California-Berkeley and Paul R. and Anne H. Ehrlich, of the Center for Conservation Biology at Stanford University, said that figure, 'if achieved reasonably soon, would also likely permit the maximum number of Homo sapiens to live a good life over the long run'. 'Determination of an "optimum" world population size involves social decisions about the life-styles to be lived and the distribution of those life-styles among individuals in the population', the scientists continued.

\section{Problems of Choice}

Between a minimum viable population-size (one just large enough to ensure against extinction) and the maximum number that can be supported by Earth's life-support systems ('housed and nurtured by methods analogous to those used to raise battery chickens'), determining an optimum becomes a problem of choosing what life-styles are to be led.

Community-level, national, and international, discussions of life-style preferences will be required before population-size targets can be established.

The team predicated their estimate on a desire to preserve the great diversity of human cultures and also to secure basic human well-being for all the world's people, 
including future generations. 'In general, we would choose a population size that maximizes very broad environmental and social options for individuals', they said. 'For example the population of the United States should be small enough to permit the availability of large tracts of wilderness for hikers and hermits, yet large enough to create vibrant cities that can support complex artistic, educational, and other cultural, endeavors that lift the human spirit.'

Daily and the Ehrlichs affirmed that, as the world's present population has already exceeded 5.6 thousand millions, even if the optimum were actually 4 thousand millions, the policy implications of our conclusions are still clear.' In other words, any reasonable optimum has already been passed; thus, not only a halt to growth, but subsequent shrinkage, is required.

It will be decades before growth can be halted and shrinkage begins -- givong plentiful time to reach a consensus on what is the optimum size and where the shrinkage should be stopped.

\section{Energy Consumption Bases}

The Daily-Ehrlichs team arrived at their estimate of the optimum by 'using humanity's energy Consumption as a rough indirect measure of the total impact of civilization on Earth's life-support systems.' The use of energy - 'especially that provided by fossil fuel and biomass combustion' - directly reflects or underpins activities that cause many global environmental problems: 'Air and water pollution, acid precipitation, land degradation, emissions of carbon dioxide and other greenhouse gases, and production of toxic and hazardous materials and wastes.'

Today's technologies and total energy consumption of 13 trillion watts (13 terawatts) already cause serious environmental deterioration and are clearly not sustainable in the long run. Each American, on average, contributes almost 12,000 watts (12 kilowatts) to that total more than 10 times that of the average citizen of a poor nation.

'Suppose population growth halted at 14 thousand millions and everyone were satisfied with a per caput energy use of 7.5 kilowatts, the average in rich nations [being] about two-thirds of that in the United States in the early 1990s. A human enterprise that large would create a total impact of 105 terawatts, eight times that of today and a clear recipe for ecological collapse', the research team concluded.

The article describes energy expert John P. Holdren's optimistic scenario in which population growth stops at 10 thousand millions and both rich and poor nations converge at a level of energy-use that is less than one-third of the current American level. That level could be reached with technologies now in hand, and with an increase in the quality of life for Americans.

As the current 13-terawatts world is clearly unsustainable, 'one might postulate that, with careful choices of energy sources and technologies, 9-terawatts might be used without degrading environmental systems and dispersing non-renewable resources any more rapidly than they could be repaired or substituted for. Under similar assumptions, a 6-terawatts world would provide a 50 percent margin for error', Daily and her colleagues contended.

\section{Reduction for Sustainability}

The team considered a generous margin of error to be essential, in view of the history of unforeseen environmental threats such as the destruction to the stratospheric ozone shield. At 3 kilowatts per person, a 6-terawatts world implies 2 thousand millions of people - about the number alive in $\mathrm{AD} 1930$. That was sufficient people to allow for 'many great cities, giant industries, and thriving arts and letters. A great diversity of cultures existed, and members of many of them were not in contact with industrialized cultures. Large tracts of wilderness remained in many parts of the world... A world with 1.5 thousand million people using 4.5 terawatts of energy seems equally plausible and would carry a larger margin of safety. This is about the same number of people as existed at the turn of the century.'

PETER RAPALUS
Stanford University News Service
Press Courtyard, Santa Teresa Street
Stanford
California $94305-2245$
USA.

Peter Rapalus Press Courtyard, Santa Teresa Street California 94305-2245

USA.

\section{Small Islands Most Vulnerable to Natural Disasters}

$\mathrm{T}^{\mathrm{s}}$ he "sustainable development of Small Island States is considerably threatened due to their vulnerability to natural disasters and the threat of global warming which is expected to result in sea-level rise', Professor G.P. Obasi, Secretary-General of the World Meteorological Organization (WMO), told participants of the UN Conference on the Sustainable Development of Small Island Developing States which was held recently in Bridgetown, Barbados, West Indies.

Most of the world's Small Island Developing States lie in or just outside the tropics, thus making them susceptible to the ravages of tropical cyclones and other natural disasters, with often devastating results on their economies and societies. An average of 80 tropical cyclones, also known as typhoons or hurricanes, form over tropical waters every year, producing winds in excess of $120 \mathrm{~km}$ per hour and sometimes up to $300 \mathrm{~km}$ per hour in severe cases, along with associated floods and storm-surges. 'Any single event which causes a loss of life and great destruction can reverse years of development', Professor Obasi said, adding 'the high cost of reconstruction and rehabilitation, along with the escalating insurance costs, are putting considerable strains on the fragile economies of small islands which depend highly on tourism and other coastal activities'.

Efforts to reduce the impact of natural hazards are often hampered by the fact that their irregularity and uncertainty foster the notion that they do not require the urgent attention of governments, said the WMO SecretaryGeneral, adding that social and economic losses could be reduced by putting in place organized systems within the communities, to prepare for and combat their impacts: 'These systems must include long-term measures aimed at 